\title{
Ecological fits, mis-fits and lotteries involving insect herbivores on the invasive plant, Bunias orientalis
}

\author{
Jeffrey A. Harvey • Arjen Biere • Taiadjana Fortuna • Louise E. M. Vet • \\ Tim Engelkes • Elly Morriën • Rieta Gols • Koen Verhoeven · Heiko Vogel • \\ Mirka Macel • Hanna M. Heidel-Fischer • Katharina Schramm • \\ Wim H. van der Putten
}

Received: 9 April 2009/ Accepted: 11 January 2010/Published online: 23 January 2010

(C) The Author(s) 2010. This article is published with open access at Springerlink.com

\begin{abstract}
Exotic plants bring with them traits that evolved elsewhere into their new ranges. These traits may make them unattractive or even toxic to native herbivores, or vice versa. Here, interactions between two species of specialist (Pieris rapae and P. brassicae) and two species of generalist (Spodoptera exigua and Mamestra brassicae) insect herbivores were examined on two native crucifer species in the Netherlands, Brassica nigra and Sinapis arvensis, and an exotic, Bunias orientalis. Bu. orientalis originates in eastern Europe and western Asia but is now an invasive pest in many countries in central Europe. $P$. rapae, $P$. brassicae and $S$. exigua performed very poorly on $\mathrm{Bu}$. orientalis, with close to $100 \%$ of larvae
\end{abstract}

J. A. Harvey $(\bowtie) \cdot$ A. Biere · T. Fortuna ·

L. E. M. Vet - T. Engelkes · E. Morriën .

K. Verhoeven - M. Macel - W. H. van der Putten

Department of Terrestrial Ecology, Centre for Terrestrial

Ecology, Netherlands Institute of Ecology, P.O. Box 40,

Boterhoeksestraat 48, 6666 ZG Heteren, The Netherlands

e-mail: j.harvey@nioo.knaw.nl

L. E. M. Vet · R. Gols

Laboratory of Entomology, Wageningen University, $6700 \mathrm{EH}$ Wageningen, The Netherlands

H. Vogel · H. M. Heidel-Fischer

Department of Entomology, Max Planck Institute of Chemical Ecology, 07745 Jena, Germany

K. Schramm

Department of Biochemistry, Max Planck Institute of Chemical Ecology, 07745 Jena, Germany failing to pupate, whereas survival was much higher on the native plants. In choice experiments, the pierid butterflies preferred to oviposit on the native plants. Alternatively, $M$. brassicae developed very poorly on the native plants but thrived on Bu. orientalis. Further assays with a German $B u$. orientalis population also showed that several specialist and generalist herbivores performed very poorly on this plant, with the exception of Spodoptera littoralis and M. brassicae. $B u$. orientalis produced higher levels of secondary plant compounds (glucosinolates) than B. nigra but not $S$. arvensis but these do not appear to be important factors for herbivore development. Our results suggest that $\mathrm{Bu}$. orientalis is a potential demographic 'trap' for some herbivores, such as pierid butterflies. However, through the effects of an evolutionary 'lottery', $M$. brassicae has found its way through the plant's chemical 'minefield'.

Keywords Brassica - Bunias - Demographic trap · Glucosinolates - Herbivore - Invasive plant . Mamestra $\cdot$ Pieris $\cdot$ Sinapis $\cdot$ Spodoptera

\section{Introduction}

The theory of co-evolution constitutes a long-standing foundation in understanding various aspects of plant-insect interactions (Ehrlich and Raven 1964; Fox and Morrow 1981; Jermy 1984; Bernays and 
Graham 1988; Janz et al. 2001). In this scenario, plants evolve defences that repel or deter herbivore attack, whereas herbivores evolve counter adaptations to deal with plant defences. Ultimately this leads to an evolutionary 'arms race' whereas some measure of equilibrium is maintained between plant response to herbivory and insect-counter-response over time (Thompson 1988). Such an arms race is predicted to lead to specialization in herbivore diet, leading to intimate associations between plants with phylogenetically conserved chemical defences and certain herbivore lineages (Feeny 1976). The larvae of many species of butterflies in the family Pieridae, for example, feed only on plants in the order Brassicales that produce secondary compounds known as glucosinolates (Gols et al. 2008a; Hopkins et al. 2009). Adaptation to specific allelochemicals may explain why polyphagy is rare amongst insect herbivores, even amongst so-called 'generalists'. This is because specific genotypes or populations of some apparent generalists tend to be found only on certain plants or else avoid plants in many families (Weis and Berenbaum 1989; Novotny and Basset 2005; Singer and Bernays 2008).

Many associations in nature, however, are not necessarily the result of long periods of co-evolution but are based on recent novel precedents. Novel associations amongst plants and herbivores may occur when an insect enters a community in which there are plants with which it is naïve, or when an exotic plant invades the range of an insect (Agosta and Klemens 2008). Described as 'ecological fitting' (Agosta 2006; Agosta and Klemens 2008), organisms are able to persist in novel environments if an evolved trait or suite of traits they bring from their original habitat enables them to enjoy realized fitness in their new habitat. Ecological fitting represents a different way of explaining the outcome of species interactions, and is notable in that evolution is not required between either party for the formation and/or persistence of the interactions between them.

Novel interactions can have either positive or negative effects on the behaviour and development of naïve herbivores (Keeler and Chew 2008). Interactions between herbivores and potential food plants involve several steps that, if successful from the herbivore's perspective, lead to adult eclosion and reproduction. These steps include habitat location of the host plant by the herbivore, alighting on the plant by the adult female, host plant acceptance (both oviposition by the adult female herbivore and the initiation of feeding by her progeny) and host plant suitability leading to successful adult eclosion (Scriber and Slansky 1981; Udayagiri and Mason 1995; Renwick and Lopez 1999; van Loon and Schoonhoven 1999). From the perspective of the herbivore, a failure to complete any one of these steps will lead to a 'misfit' (as opposed to fitting) with the novel plant. Novel plants may also become demographic traps if they are highly attractive to an insect on which their progeny perform very poorly (Renwick 2002; Keeler et al. 2006; Keeler and Chew 2008). On the other hand, they present evolutionary opportunities if herbivores can adapt to them.

Many studies involving novel interactions between plants and insect herbivores are based on exotic plants that have become established in new habitats (Agrawal et al. 1999; Louda et al. 2005; Siemann et al. 2006; Lankau and Strauss 2007). Plants that invade regions bordering their natural range, perhaps due to such processes as changes in land use or climatic warming may encounter novel herbivore species that exhibit differing degrees of adaptation to their secondary (= defensive) metabolites (Engelkes et al. 2008). The nutritional suitability of food plants is influenced by both levels of toxic secondary plant metabolites and nutrients found in plant tissues (Slansky 1992). In areas close to the natural range of the invasive plant, populations of many herbivores may be adapted to secondary metabolites in the exotic plant, particularly if the plant shares common secondary metabolites with other native food plants used by the herbivore. Closely related plants often possess chemical 'fingerprints' based on their secondary chemistry which are recognized by specialized insect herbivores (Feeny 1976; Müller-Schärer et al. 2004). However, novel secondary plant metabolites may lead to mis-fits between the plant and the herbivore, making these plants nutritionally unsuitable or even toxic to the herbivore (Renwick 2002; Verhoeven et al. 2009).

The warty cabbage, Bunias orientalis L. (Capparales: Brassicaceae) is a wild cruciferous plant that originates in western Asia and extreme eastern Europe but which has become an highly invasive species in various parts of northern and central Europe over the past 25 years (Dietz et al. 1996; Woitke and Dietz 2002). For instance, it is now 
considered to be a serious pest in parts of Germany, Poland, Sweden, Norway, as well as in several other countries (Dietz et al. 1999). At the same time, the plant is less common in parts of western Europe, including the Netherlands, Britain, France, and Austria (Dietz et al. 1996). Where it is invasive, stands of $B u$. orientalis may form dense monocultures in ruderal areas such as roadsides and waste ground, but the plant apparently can also out-compete midsuccessional vegetation and agricultural crops (Dietz et al. 1996). Like all brassicaceous plant species, $B u$. orientalis is able to biosynthesize secondary plant compounds called 'glucosinolates' (GS). These compounds play an important role against a range of attackers and are especially effective in reducing the performance of generalist herbivores (Chew 1988; Rask et al. 2000).

In this study we compare the development and survival of two specialist herbivores, Pieris rapae L. and P. brassicae L. (Lepidoptera: Pieridae) and two generalist herbivores, Spodoptera exigua Hübner and Mamestra brassicae L. (Lepidoptera: Noctuidae) on an accession of $\mathrm{Bu}$. orientalis originating from a population in the Netherlands, as well as on two native Dutch crucifers, Brassica nigra L. and Sinapis arvensis L. (Capparales: Brassicaceae). These two crucifers were deliberately selected because they are abundant and ubiquitous during the growing season, produce large amounts of biomass and serve as the two most important naturally occurring food plant species for caterpillars of both $P$. rapae and P. brassicae over much of Eurasia (Feltwell 1982; Gols et al. 2008b). We also examine oviposition behaviour and preference in the two pierids on the three cruciferous plants. The cabbage moth $M$. brassicae, on the other hand, is commonly found on cultivated crucifers such as cabbage which have depressed levels of GS in shoots (Gols et al. 2008a).

Additional assays were conducted in which several species of generalist herbivores in the Noctuidae (including $M$. brassicae and S. exigua) and both pierids were reared from their 1st (L1) and 3rd (L3) instars on a German accession of Bu. orientalis. This enabled us to determine if the biological effects of this plant (if any) are similar in plants growing in different regions of central Europe.

The main aims of the study are (1) to determine if the performance of the specialist and generalist herbivores differs on three crucifers, (2) to determine if oviposition preference of the two pierids differs on the three crucifers and is correlated with performance, and (3) to compare GS levels in healthy plants and plants damaged by larvae of $S$. exigua. Our main hypotheses are (1) that, irrespective of plant species origin, the development of the generalist herbivores will be negatively correlated with total glucosinolate levels as has been demonstrated in other studies with generalists developing on wild perennial crucifers such as wild cabbage (Gols et al. 2008a), and (2) that the development and oviposition preference of the specialist herbivores will be less affected on the different crucifers because they are adapted to the main secondary compounds (GS) contained in these plants (Hopkins et al. 2009).

\section{Materials and methods}

All experiments with plants and insects using Dutch accessions were maintained in climate rooms at $22 \pm 2{ }^{\circ} \mathrm{C}$ with a 16:8 h L:D photoperiod. This closely approximates the length of daylight in the Netherlands in the period between June and August.

Plants

$B u$. orientalis is a perennial plant that may live up to 10 years or even longer. The seeds germinate in autumn with new rosettes produced the following year that consist of up to hundreds of leaves. Furthermore, the roots of parent plants may produce horizontal stems below ground, which produce spatially extensive networks of interconnected, yet functionally autonomous plants. Plants typically begin to flower in early May and produce fruits that are ripe by late July. Seeds of $S$. arvensis also germinate in late autumn and begin growing the following spring. Plants usually flower in May and produce seeds in late June, although occasionally there is a second generation later in the year. The lifecycle of $B$. nigra is similar, except that the plants generally do not flower until mid-July. $S$. arvensis and B. nigra are annuals with short life-cycles. However, because they grow quickly in ruderal sites, they are capable of producing significant aboveground plant biomass which is visible for about 8 weeks in the growing season. As stated earlier, both species serve as major food plants for spring and 
summer generations of some specialist herbivores, most notably larvae of large and small cabbage butterflies (Gols et al. 2008a).

Seeds of $B u$. orientalis were obtained from an established wild population growing along a railway line mid-way between Arnhem and Nijmegen, the Netherlands, within a few hundred meters of the River Rhine. The plants from this population originated from a small cluster of $\sim 5$ plants. Seeds of B. nigra and $S$. arvensis were obtained from wild plants growing naturally in large single populations in Wageningen, the Netherlands. For the German assays, plant leaves were collected during late summer from plants growing in fields adjacent to the Max Planck Institute, Jena, Germany.

The seeds of $\mathrm{Bu}$. orientalis were extracted from dried fruits by gently cracking them open using a nutcracker. The seeds of the other crucifers were extracted from dried pods by hand. In all species the seeds were allowed to germinate in small plastic boxes $(15 \times 10 \times 6 \mathrm{~cm})$ containing glass beads immersed in tap water. Newly germinated seedlings were grown in 21 plastic pots containing a soil mixture consisting of approximately $30 \%$ sand, 5\% clay, and $65 \%$ peat. Plants were grown in a greenhouse at $22 \pm 2{ }^{\circ} \mathrm{C}, 50-70 \%$ r.h, with a photoperiod of at least $16 \mathrm{~h}$. Natural daylight was supplemented by metal-halide lamps $\left(225 \mu \mathrm{mol}\right.$ photons $\left./ \mathrm{m}^{2} / \mathrm{sec}\right)$ during the $16 \mathrm{~h}$ photoperiod. Plants were watered daily, and after 2 weeks they were provided with nutrient-enhanced Hoagland solution to compensate for nutrient depletion in the soil. All the plants used in the herbivore development and oviposition assays were between 4 and 5 weeks old.

\section{Distribution of Bunias orientalis}

The Atlas Florae Europaeae (AFE) (Jalas and Suominen 1972-1994) has calculated the presence or absence of 2432 species of plants using grid cells that are approximately $50 \mathrm{~km}^{2}$ but which vary according to latitude and longitude. These data have been combined with personal communication with other researchers in many countries throughout Europe where $\mathrm{Bu}$. orientalis is either present or absent. An estimate of the current native, invasive and exotic (not yet invasive) range for Bu. orientalis is presented in Fig. 1.

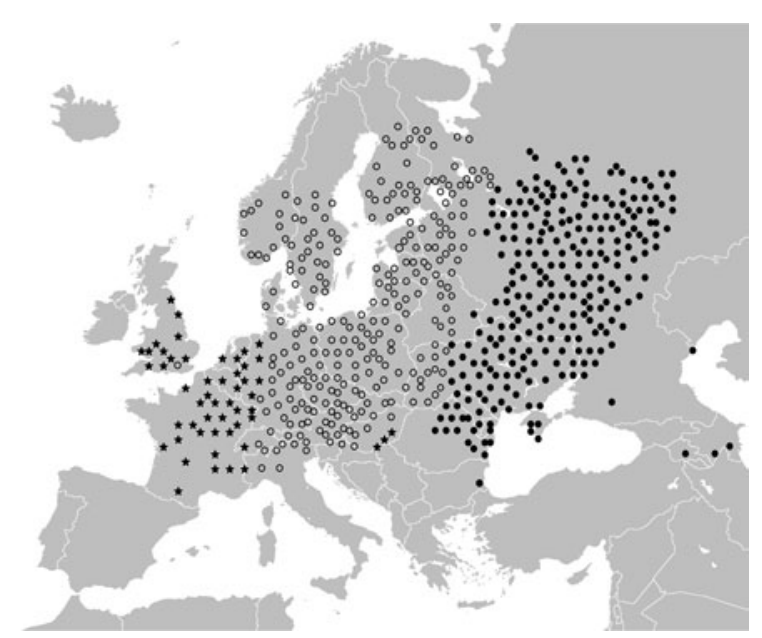

Fig. 1 Distribution map of Bunias orientalis in Europe and western Asia. Black circles indicate area where Bu. orientalis is native; open circles where the species is highly invasive; black stars where the species is present but as of yet noninvasive. Data from Atlas Florae Europaeae (AFE) and in personal communication with various institutions throughout Europe

\section{Insects}

The small (P. rapae) and large (P. brassicae) cabbage white butterflies are native over much of Eurasia and are pests in collard crops. Adults of $P$. rapae lay single eggs on the underside of leaves, and the larvae, which are green in colour, feed solitarily. After completing 5 instars, the larvae pupate on plant stems or leaves. By contrast, female $P$. brassicae butterflies lay broods of up to 150 eggs on the underside of the leaves, and after hatching the dark green larvae feed gregariously until their third instar. They then disperse on the food plant and become yellow and black in colour, feeding on both leaves and flowers (Smallegange et al. 2007). After completing 5 instars, the larvae pupate on the food plants. Eggs of both pierid species were obtained from cultures maintained at the Laboratory of Entomology, Wageningen University (WUR) the Netherlands for many years. The insects were originally collected from agricultural fields in the vicinity of the University. Both species are reared on Brussels sprouts plants (B. oleracea var. gemmifera cv Cyrus). Although they readily oviposit and feed on a number of wild crucifers (Feltwell 1982), little is known about their natural association, if any, with exotic species such as $\mathrm{Bu}$. orientalis. 
The cabbage moth, $M$. brassicae, is a generalist herbivore that feeds on a wide variety of plants. It is native to Eurasia and is also a serious pest in collards and other cruciferous crops as well as in beet and onion fields. Large numbers of this species have been observed feeding on $\mathrm{Bu}$. orientalis plants in Germany (J. Harvey, personal observations). The southern beet armyworm, $S$. exigua is a generalist herbivore whose larvae feed on a very wide range of plants in several different families. Its life cycle is similar to that of M. brassicae (Carter 1984). The species is a well-established pest of crop species over much of the world. Both noctuids lay their eggs directly onto the food plant and their larvae complete 5 instars before dropping to the soil to pupate. Eggs of M. brassicae and S. exigua were also obtained from cultures maintained at the Laboratory of Entomology at WUR. Larvae of S. exigua were reared on artificial diet as described by Vickerman and Trumble (1999). Adult moths were kept in groups of 5-10 in 11 plastic beakers containing vermiculate, with water absorbed in cotton wool added in small plastic vials. Paper sheets were placed around the inside of the beakers as well as over the top, which was secured with an elastic band. Female moths oviposit directly onto the paper and newly hatched larvae were placed onto artificial diet in small plastic boxes. M. brassicae are reared on Brussels sprouts plants as described for both Pieris species (above). Adult moths were also kept in 11 beakers and eggs were collected in the same fashion as with $S$. exigua.

For experiments with the German accession of $B u$. orientalis experiments used the following insects: Cotton bollworm (Helicoverpa armigera, Toowoomba strain [Australia], cabbage moth (Mamestra brassicae), beet armyworm (Spodoptera exigua), cotton leafworm (Spodoptera littoralis, both species obtained as lab strains from BAYER) and tobacco budworm (Heliothis virescens, YDK strain obtained from North Carolina; Gould et al. 1995). Larvae were reared on a laboratory-prepared pinto bean diet (Perkins et al. 1973) and held in a climatic-controlled room at $25^{\circ} \mathrm{C}, 16: 8$ (L:D) photoperiod, and $60 \% \mathrm{RH}$ until used for experiments. Cultures of $P$. rapae and $P$. brassicae were originally obtained from Seritech (Warwick, UK) and reared on Brassica oleracea gemmifera cv. Rosella at $22^{\circ} \mathrm{C}$ and $70 \%$ humidity with a 16:8 (L:D) photoperiod. Both cultures were supplemented with individuals from Jena, Germany, to reduce the risk of inbreeding.

Experimental protocol

\section{Development of insect herbivores on Dutch populations of Brassica nigra, Sinapis arvensis and Bunias orientalis}

Egg batches of $P$. rapae and $P$. brassicae were allowed to hatch on excised Brussels sprouts leaves and the neonate larvae were then carefully removed with a soft brush and transferred to experimental plants in large rearing cages $(40 \times 25 \times 35 \mathrm{~cm})$. Larvae were placed in groups of 20 on middle-aged leaves of single plants, and were then allowed to freely disperse on the plants. In addition to the plants containing larvae, an additional 2 plants were placed into the cages to ensure that the caterpillars had sufficient food. No more than 40 larvae were maintained in a single cage. As they grew and moulted, larvae were distributed to other cages containing fresh food plants. In total, larvae of $P$. rapae and $P$. brassicae were reared on no less than 16 plants of each species. Mature larvae crawl to the top of the cages where they initiate pupation. Fresh pupae of both pierids were carefully removed from the cages and weighed on a Mettler-Toledo MT5 Electrobalance (accuracy $\pm 1 \mu \mathrm{g}$ ). In order to determine larval mortality, initial (L1) larval and terminal (pupal) counts were made for all herbivoreplant combinations. Mortality was determined as the percentage of neonate larvae that failed to pupate. Two replicates of the experiment were performed: the first between May and July of 2006 and the second between April and June of 2007. In the first replicate, 25 larvae were also randomly selected from each plant species and weighed on the microbalance when they were 10 days old (post hatching). Because many of the $P$. rapae and $P$. brassicae larvae had already died on $B u$. orientalis plants, the sample sizes for these species on $B u$. orientalis was smaller than on either $S$. arvensis or B. nigra.

Cohorts of newly hatched larvae of S. exigua and $M$. brassicae were allowed to feed on excised leaves of the three food plant species that were kept in separate in plastic boxes for the first 2 days. Approximately 60 larvae were then individually removed from the boxes and placed individually into small clip 
cages ( $3 \mathrm{~cm}$ dia.) on mid leaves of their respective food plants. No more than 5 larvae were allowed to feed on a single plant. The clip cages were checked daily and were moved to another part of the same leaf if more than half of the leaf tissues under the cage had been consumed. On the 8th day, the larvae of both species were transferred to large clip cages $(8 \mathrm{~cm}$ dia.) and these were placed onto new food plants. Because they are small, 3-5 larvae of S. exigua were maintained in a single clip cage, whereas the large $M$. brassicae were kept singly. The $S$. exigua experiment was based on a single replicate performed in April-May, 2007; two replicates were performed for $M$. brassicae (the same times as those performed for the two pierid species). Pupal mass and mortality were determined following the same procedure as for the pierids.

The growth curves (or trajectories) of $M$. brassicae larvae were also compared on the three crucifer species. In order to compare the larval growth trajectories of $M$. brassicae, 25 larvae per plant species were reared in a separate cohort during the second replicate as described above. Every 3 days from hatching the larvae were removed from clip cages and weighed on the Mettler-Toledo MT5 Electrobalance (accuracy $\pm 1 \mu \mathrm{g}$ ). Once the larvae exceeded approximately $100 \mathrm{mg}$, they were then weighed on a Mettler-Toledo AG135 Electrobalance (accuracy $\pm 10 \mu \mathrm{g}$ ). In the first replicate, 25 larvae were also randomly selected from clip cages on each plant species and weighed on the microbalance, but in this instance when they were 12 days old (post hatching). For $S$. exigua, many of the larvae had already died on $\mathrm{Bu}$. orientalis by this time hence the sample size for this species on this plant was smaller than on either $S$. arvensis or B. nigra.

Survival of generalist and specialist herbivores on a German accession of Bunias orientalis

To determine if a different accession of Bu. orientalis has similar or different effects on the development of generalist (Noctuidae) and specialist (Pieridae) herbivores, assays were conducted at the Max Planck Institute. Eggs of the 5 generalist herbivores (Heliothis virescens, Helicoverpa armigera, $H$. subflexa, $S$. exigua, $S$. littoralis and $M$. brassicae were collected from paper lids overlying plastic containers. Newly hatched L1 larvae were reared in groups of 40 in large plastic tubs $(40 \times 20 \times 20 \mathrm{~cm})$ that were covered with a fine nylon mesh. In these tubs they were provided with a constant supply of excised leaves of $\mathrm{Bu}$. orientalis that had been collected from plants growing close to the Institute. A separate cohort of older caterpillars was taken from artificial diet as early L3 and placed in groups of 40 into separate containers. Leaves were also refreshed every 2 days as required. Pieris rapae and P. brassicae were reared in the same way as the noctuids, except that for the L3 treatment the larvae were removed from intact cabbage plants and reared on excised $B u$. orientalis leaves. For all insects, survival was monitored daily and any dead larvae were immediately removed from the experiment and were counted. Survival was based on the number of larvae that were able to pupate successfully.

Oviposition behaviour in Pieris rapae and P. brassicae when provided with Sinapis arvensis, Brassica nigra and Bunias orientalis plants

In order to determine if adult female $P$. rapae and $P$. brassicae butterflies exhibit differences in preference for oviposition sites, an experiment was set up comparing the number of eggs laid on $S$. arvensis, $B$. nigra and $B u$. orientalis plants. Because it is gregarious, total clutches of eggs laid were also counted in $P$. brassicae. Before the experiment was performed, it was necessary to show that both butterflies do not lay their eggs randomly on any available plants. In two small cages $(30 \times 25 \times$ $25 \mathrm{~cm}$ ) several female butterflies of each species were presented with either cultivated cabbage or black mustard plants, as well as with either lima bean (Phaseolus lunatus) or tomato (Solanum lycopersicum) plants. The latter two species are non-brassicaceous and do not produce GS. In both trials, butterflies laid eggs only on the cabbage or mustard plants, and thus completely ignored the non-crucifers (data not shown). This revealed that the insects sample the plants before ovipositing and thus do not lay their eggs randomly.

Two female and two male butterflies that were approximately 5 days old were placed into large indoor cages $\left(1.1 \mathrm{~m}^{3}\right)$ each containing 2 mature $S$. arvensis, B. nigra and $B$. oreintalis plants that were 4-5 weeks old in a large greenhouse room (maintained at a constant $25^{\circ} \mathrm{C}$ with $16 \mathrm{~h}$ light). Because 
$B u$. orientalis plants are not as tall as plants of the other species, they were placed on $20 \mathrm{~cm}$ stands that made them of equivalent height. The butterflies were supplied with $20 \%$ sugar solution in small Eppendorf tubes that had been placed into the centre of plastic yellow and blue flowers attached to wooden sticks on stands. Both species were kept separately in cages with plants, and the butterflies were removed after $24 \mathrm{~h}$ and the eggs (as well as egg clutches for $P$. brassicae) were counted. There were 10 replicates for $P$. rapae and 12 for P. brassicae.

Glucosinolate analyses of leaf tissues of Sinapis arvensis, Brassica nigra and Bunias orientalis

To compare the quality and quantity of GS in leaf tissues of the three plant species, leaf tissues were collected from undamaged control plants and plants that had been damaged by $S$. exigua larvae for 5-7 days. This herbivore species was used because it was the one species which during early development fed about equally on the three plant species, meaning that damage was more uniform than in the case of the other herbivores. The distal parts (approximately $20 \mathrm{~cm}^{2}$ ) were cut from all fully developed leaves of a plant individual, pooled, and immediately stored in paper bags at $-20^{\circ} \mathrm{C}$. Eight samples were collected from each of the plant species for both treatments (damaged and control). Undamaged and damaged plants were of the same age and were sampled on the same date. Samples were freeze-dried and pulverized. GS were extracted from $40 \mathrm{mg}$ of ground leaf material in boiling $70 \%$ methanol. The extract was purified and desulfated on a DEAE-Sephadex A26 column. The desulfated GS were separated on a reverse phase $\mathrm{C}-18$ column (Alltima C-18, $3 \mu \mathrm{m}, 150 \times 4.6 \mathrm{~mm}$, Alltech, Deerfield, IL, USA) on HPLC (Dionex, Sunnyvale, CA, USA) with an acetonitrile water gradient. Detection was performed with a Dionex PDA-100 Photodiode array detector set to scan from 200 to $350 \mathrm{~nm}$. For quantification, sinigrin (Sigma, St. Louis, IL, USA) was used as an external standard. Peaks were integrated at $229 \mathrm{~nm}$ for which standard response factors have been defined. The different GS were identified based on their retention times and UV spectra compared to those of pure compounds, sinigrin (Sigma, St, Louis, IL, USA), glucotropaeolin, sinalbin, and glucobrassicin, or compared with a certified oil seed reference (EC Community).

\section{Statistical analyses}

Development data: Effect of plant species, block, and their interactive effect on survival of the pierids and $M$. brassicae larvae to the pupae stage were tested using Generalized Linear Models (procedure GENMOD in SAS v. 9.1) with a type III binomial distribution and logit link function. For S. exigua, only one time block was performed and hence only the effect of plant species was tested. Effects of plant species on larval mass was analysed using one-way analysis of variance (ANOVA). Effects of plant species, time block, and their interactive effect on pupal mass and development data were analysed using 2-way ANOVA (procedure GLM, SAS v. 9.1, SAS Institute Inc., Cary, NC, USA). No data transformation was necessary to meet assumptions of normality and homogeneity of variances. Effects of cage, host plant species, and interactions between cage and host plant species on oviposition were analysed with Generalized Linear Models also using SAS v. 9.1 procedure GENMOD on $(x+1$ transformed) count data with a type III Poisson error distribution and a log link function. Contrasts within the factor host plant species were used to test differences in oviposition between the three host plant species.

\section{Results}

Development and survival of generalist and specialist herbivores on Brassica nigra, Sinapis arvensis, and Bunias orientalis plants

Survival of $P$. rapae larvae to the pupal stage was strongly dependent on the identity of the plant species $\left(\chi_{2}^{2}=291.23, P<0.001\right)$. Effects of replicate and interactions with replicate were not significant. In both replicates, all larvae perished on $\mathrm{Bu}$. orientalis plants, with most failing to survive during the first instar. By contrast, survival was over $70 \%$ in both of the native crucifers (Fig. 2a). Body mass in 10-day old larvae of $P$. rapae varied significantly across the different plant species $\left(F_{2,56}=68.66, P<0.001\right)$. 

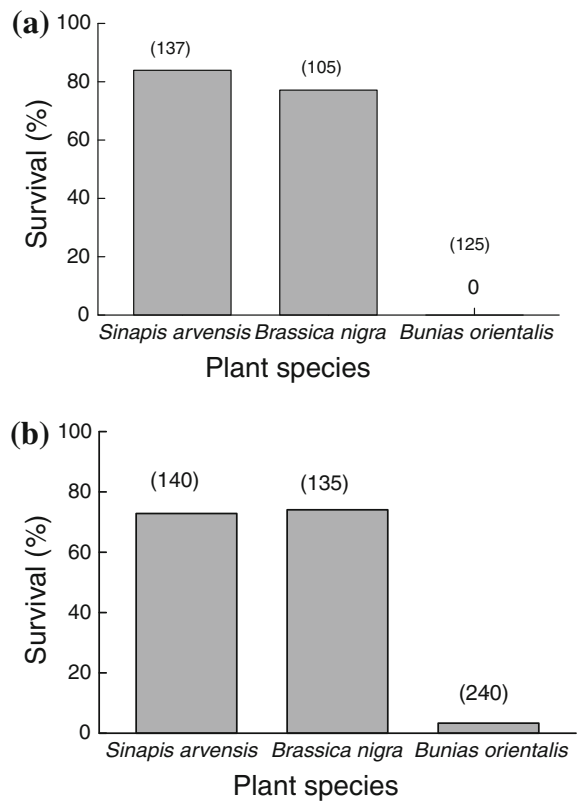

Fig. 2 Survival of different insects on Sinapis arvenis, Brassica nigra and Bunias orientalis plants. a Pieris rapae, b P. brassicae,

Only 9 larvae reared on $\mathrm{Bu}$. orientalis survived this long, and they were a small fraction of the size of larvae developing on the native crucifers (Fig. 3a). Pupal mass in $P$. rapae varied significantly with replicate $\left(F_{1,195}=125.62, P<0.001\right)$ and between the two native plant species $\left(F_{1,195}=25.63\right.$, $P<0.001)$ whereas the interactive effect of these parameters was not significant $\left(F_{1,195}=2.21\right.$, $P=0.138$ ). Insects developing in the second replicate were smaller than those developing in the first replicate (see "Materials and methods") and B. nigra plants were of somewhat higher quality than S. arvensis plants for this herbivore (data not shown).

Survival of $P$. brassicae larvae also was significantly associated with the identity of the food plant $\left(\chi_{2}^{2}=356.34, P<0.001\right)$. As with its congener, $S$. arvensis and $B$. nigra were much more suitable plants than $B u$. orientalis, with more than $70 \%$ of larvae pupating on the natives. In the second replicate, all larvae perished on $\mathrm{Bu}$. orientalis plants, whereas approximately $6 \%$ managed to pupate on this plant in the first (Fig. 2b). Overall, survival was lower in replicate $2\left(\chi_{1}^{2}=37.88, P<0.001\right)$ and the magnitude of the effect of host species was slightly affected by replicate (host species $\mathrm{x}$ replicate interaction, $\left.\chi_{1}^{2}=6.11, P<0.05\right)$. Body mass in 10 day-old
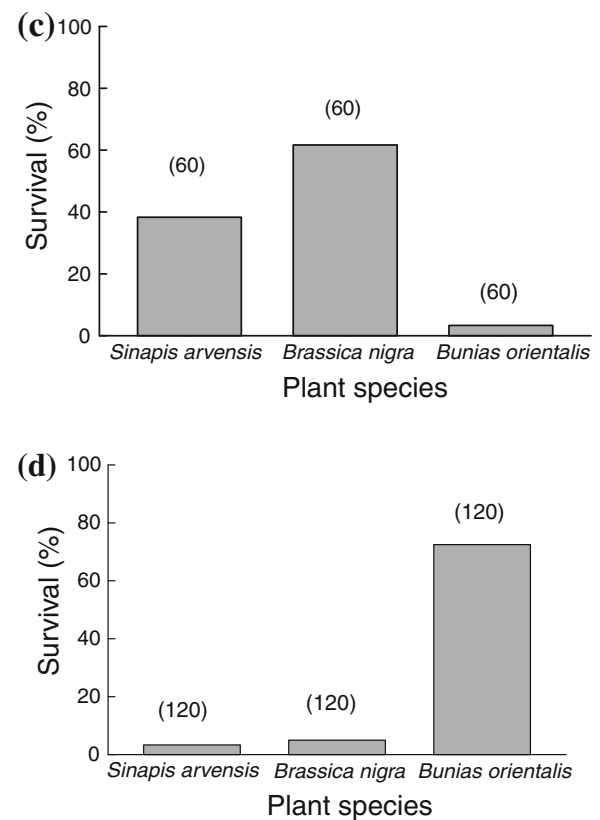

c Spodoptera exigua, d Mamestra brassicae. Sample sizes are indicated in parentheses over the bars

larvae also varied significantly with plant species $\left(F_{2,66}=62.60, P<0.001\right)$. As with $P$. rapae, larval mass in 10-day old $P$. brassicae was much lower on $B u$. orientalis plants (Fig. 3b). Pupal mass in $P$. brassicae also varied significantly between replicates $\left(F_{1,205}=9.92, P<0.01\right)$ but not between the two native crucifers $\left(F_{1,205}=0.561, P=0.436\right)$, and the interactive effect between these parameters was also not significant $\left(F_{1,205}=0.38, P=0.541\right)$. As with $P$. rapae, insects in the second replicate were smaller than in the first replicate, but the two crucifers were of similar quality. A one-way ANOVA, incorporating $B u$. orientalis pupal data from the first replicate, revealed that pupal mass differed significantly with plant species $\left(F_{2,124}=9.99\right.$, $P<0.001)$. Unlike $P$. rapae, many $P$. brassicae larvae readily fed on $\mathrm{Bu}$. orientalis plants during early larval development, but most were unable to survive beyond their third instar. Those that did manage to pupate in the first replicate were significantly smaller as pupae on $\mathrm{Bu}$. orientalis plants than on the natives.

The survival of $S$. exigua larvae was also found to be strongly associated with foodplant identity $\left(\chi_{2}^{2}=45.80, P<0.0001\right)$. Like the specialist herbivores, $S$. exigua survival was much higher on the 

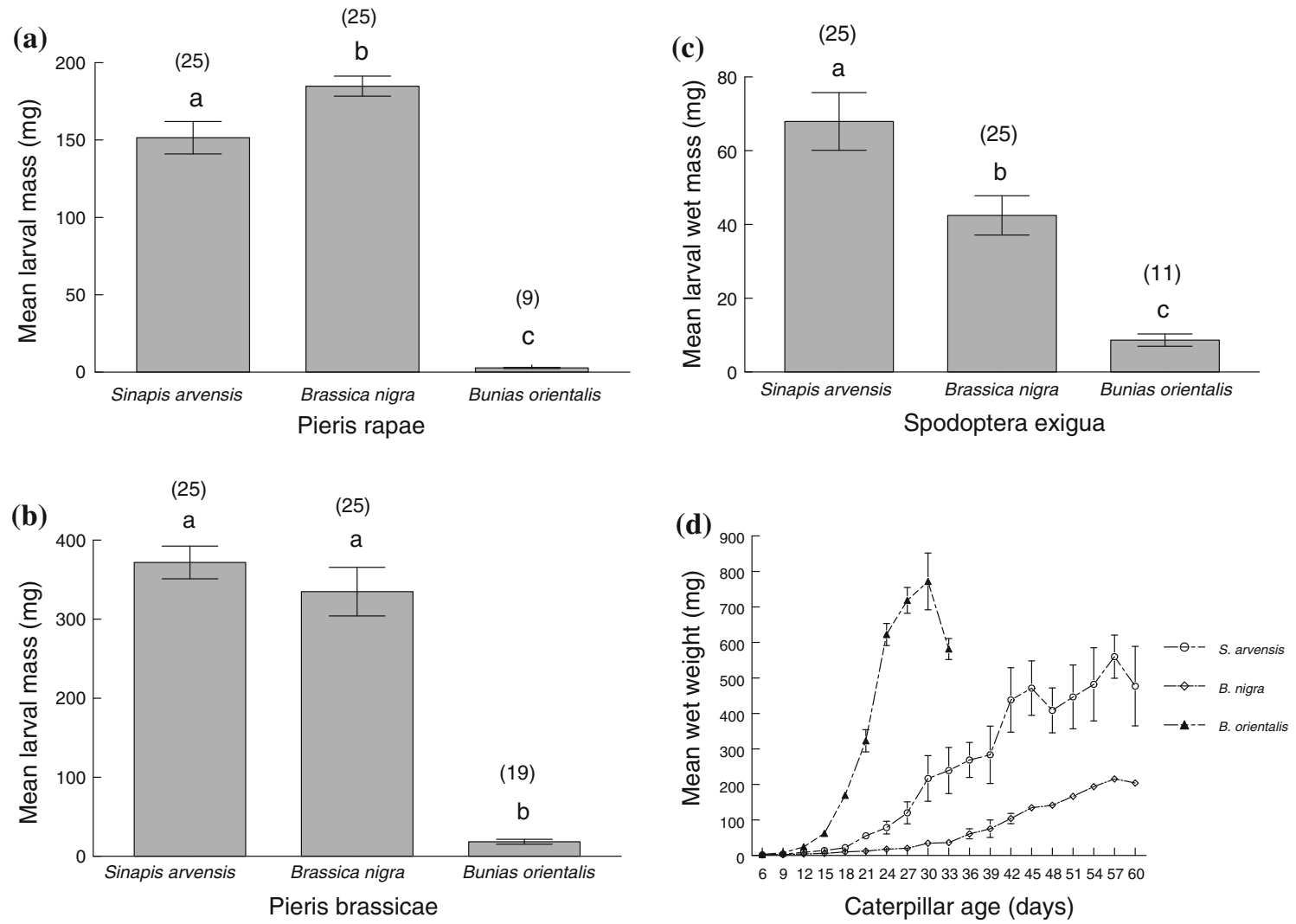

Fig. 3 a, b, c Larval wet mass at 10 days of age in different insect herbivores developing on Sinapis arvenis, Brassica nigra and Bunias orientalis plants. d Growth trajectories of Mamestra brassicae larvae from hatching until pupation or precocious death. Line bars represent standard error of the

mean. Bars with the same letter are not significantly different (Tukey-Kramer tests, $P>0.05)$. Sample sizes for $(\mathbf{a}, \mathbf{b}, \mathbf{c})$ are as indicted in parentheses over the bars. d 20 larvae per plant from hatching

native crucifers than on the invasive (Fig. 2c). The mass of 12-day old $S$. exigua larvae also varied significantly with plant species $\left(F_{2,58}=14.83\right.$, $P<0.0001)$. The pattern was similar to that in the pierids, with larval mass greatly depressed on $\mathrm{Bu}$. orientalis plants. Larvae were largest at this time on S. arvensis plants (Fig. 3c).

In $M$. brassicae, larval to pupal survival was also found to vary amongst the different plants tested $\left(\chi_{2}^{2}=218.88, P<0.001\right)$. However, the pattern differed profoundly from that described in the other species, with survival in both replicates being considerably higher on $B u$. orientalis plants than on the native crucifers (Fig. 2d). Overall survival did not differ between replicates, but the slightly higher survival of $S$. arvensis in replicate 2 and of B. nigra in replicate 1 resulted in a significant interaction between replicate and species $\left(\chi_{2}^{2}=12.88, P<0.01\right)$.

The mass of 12-day old M. brassicae larvae also varied significantly with plant species $\left(F_{2,72}=51.39\right.$, $P<0.0001)$. The pattern was, however, completely opposite to that observed in the pierids and S. exigua, with larval mass greatly depressed on the native plants and highest on $\mathrm{Bu}$. orientalis (data not shown). A comparison of the growth trajectories of M. brassicae caterpillars in the three plants revealed that larvae grew exponentially in $\mathrm{Bu}$. orientalis, exhibiting a 'J-curve'. By contrast, larval development was depressed in S. arvensis and especially on B. nigra plants (Fig. 3d).

Survival of generalist and specialist herbivores on a German accession of Bunias orientalis

Most of the insect herbivores reared on a German accession of $\mathrm{Bu}$. orientalis were not able to pupate on 
Table 1 Stage-specific and overall percentage survival $( \pm \mathrm{SD})$ of generalist and specialist herbivores in the Lepidoptera on Bunias orientalis plants (German accession)

\begin{tabular}{lllcc}
\hline Insect species & $n$ & $\mathrm{Sp} / \mathrm{Gen}$ & 1st instar & 3rd instar \\
\hline Heliothis virescens & 120 & $\mathrm{Gen}$ & $0.0(0)$ & $0.0(0)$ \\
Helicoverpa armigera & 120 & $\mathrm{Gen}$ & $0.0(0)$ & $4.2(1.6)$ \\
Heliothis subflexa & 120 & $\mathrm{Gen}$ & $0.0(0)$ & $0.0(0)$ \\
Spodoptera exigua & 120 & $\mathrm{Gen}$ & $0.0(0)$ & $0.0(0)$ \\
Spodoptera littoralis & 240 & $\mathrm{Gen}$ & $52.2(3.5)$ & $68.2(1.8)$ \\
Mamestra brassicae & 320 & $\mathrm{Gen}$ & $81.3(2.4)$ & $96.5(1.2)$ \\
Pieris rapae & 120 & $\mathrm{Sp}$ & $0.0(0)$ & $0.0(0)$ \\
Pieris brassicae & 160 & $\mathrm{Sp}$ & $0.0(0)$ & $0.0(0)$ \\
\hline
\end{tabular}

$S p$ specialist herbivores, Gen generalist herbivores

this plant, irrespective as to whether they were provided with leaves as L1 or L3 instars. Both pierids suffered $100 \%$ mortality on $\mathrm{Bu}$. orientalis as did three of the noctuids (H. virescens, $H$. subflexa and S. exigua). By contrast, S. littoralis and M. brassicae both survived well on $\mathrm{Bu}$. orientalis, with $>80 \%$ of $M$. brassicae pupating successfully (Table 1).

Oviposition behaviour in Pieris rapae and P. brassicae when provided with Sinapis arvensis, Brassica nigra and Bunias orientalis plants

Mean leaf area of the three plant species did not differ significantly when $P$. rapae butterflies were foraging $\left(F_{2,27}=3.20, P=0.06\right)$ but did so when $P$. brassicae butterflies were foraging $\left(F_{2,27}=10.175\right.$, $P<0.001)$. With respect to $P$. rapae, leaf area of $B u$. orientalis were marginally (though not significantly) greater than for the other two species. On the other hand, $B$. nigra plants had more leaf area than the other two species in cages with $P$. brassicae. However, in both experiments all of the plants had very large amounts of foliage and this was almost certainly not a limiting factor.

Pieris brassicae on average laid 3.8 egg batches (broods) per cage with an average brood size of 38.3 eggs per brood. Brood size did not differ between host plants $\left(F_{2,35}=0.06, P=0.94\right)$, but the number of oviposited broods was significantly lower on $B u$. orientalis than on B. nigra (Table 2) and the total number of oviposited eggs was significantly lower on $B u$. orientalis ( $8.2 \%$ of all eggs) than on S. arvensis
Table 2 Generalized Linear Model analysis of effects of cage and host plant species on oviposition (number of egg clusters or eggs deposited) by Pieris brassicae and Pieris rapae on three different host plant species, Brassica nigra, Sinapis arvensis and Bunias orientalis presented as three-choice in cages with three plants

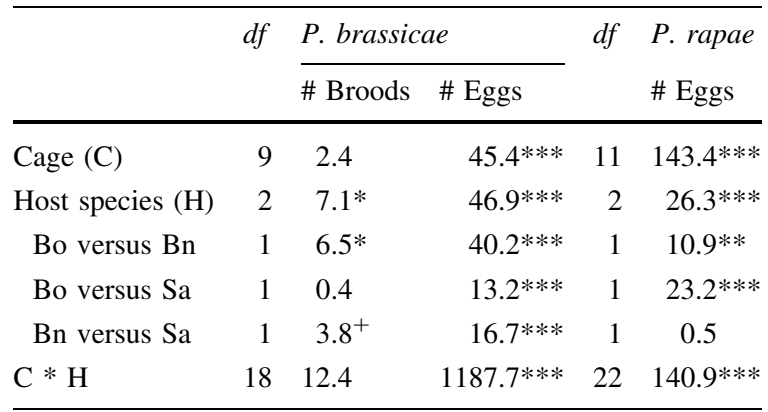

Degrees of freedom $(d f)$ and chi-square values are given

$+P<0.10, * P<0.05$, ** $P<0.01$, *** $P<0.001$

(20.0\%), both of which were lower than on B. nigra (71.8\%) (Table 2, Fig 4a). The magnitude of the host plant-specific differences in oviposition varied among cages (cage*host plant interaction, Table 2, Fig. 4a).

Pieris rapae on average laid 37.9 eggs per cage. Oviposition was significantly lower on $\mathrm{Bu}$. orientalis (13.9\%) than on S. arvensis $(38.2 \%)$ and B. nigra (47.9\%), whereas the difference between the latter two species was not significant. Like for P. brassicae, the magnitude of the host plant-specific differences varied among cages (cage*host plant interaction, Table 2, Fig. 4b).

Glucosinolate analyses in leaf tissues of Sinapis arvensis, Brassica nigra and Bunias orientalis

Analysis of glucosinolates in leaf tissues revealed considerable quantitative and qualitative variation in concentrations of these secondary plant compounds among the three plant species (Table 3). p-Hydroxybenzyl glucosinolate (also called sinalbin) is the dominant compound in both $\mathrm{Bu}$. orientalis and S. arvensis contributing $85-95 \%$ and $35-60 \%$, respectively, to the total glucosinolate content. Different aliphatic gluosinolates (glucosinolates derived from methionine) further characterized $B u$. orientalis and $S$. arvensis. In contrast, leaf tissues of $B$. nigra contained only one glucosinolate, i.e. allylglucosinolate (trivial name sinigrin), which was not found in foliar tissues of the other two plant species. In $S$. arvensis, concentrations of all the glucosinolate 


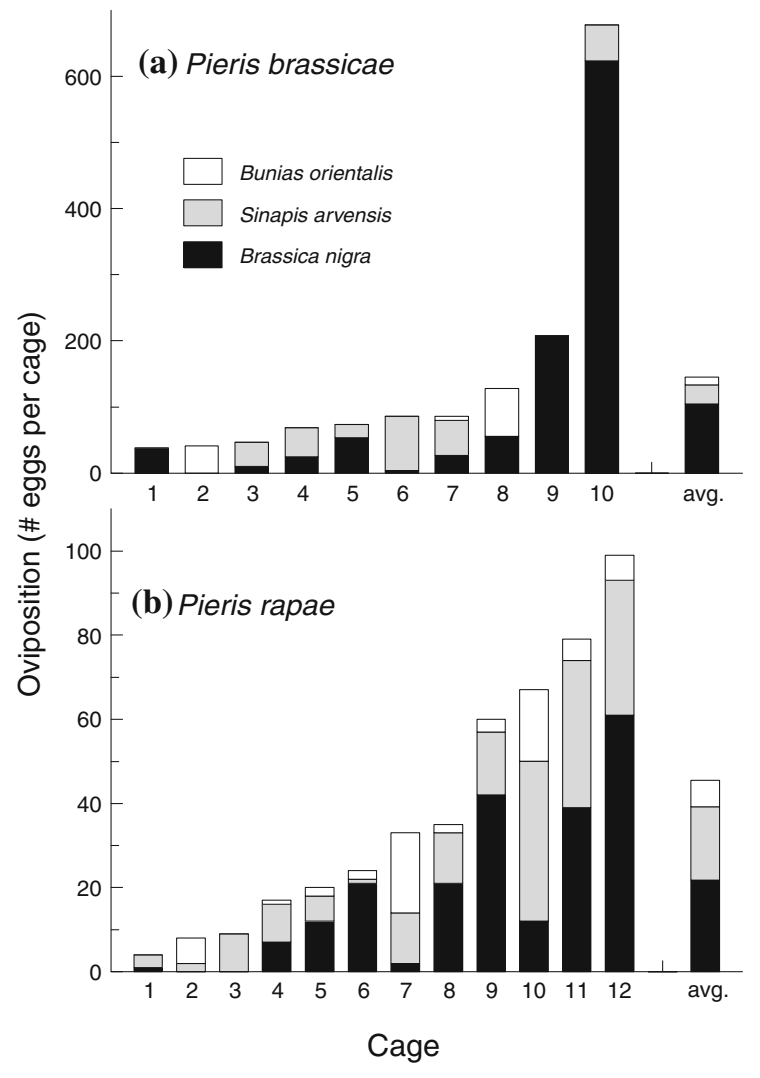

Fig. 4 Oviposition (number of eggs deposited) by a Pieris brassicae and $\mathbf{b}$ Pieris rapae on plants of three different host species offered in a three-choice experiment (three plants per cage). There were two female and 2 male butterflies per cage over the course of $24 \mathrm{~h}$

compounds increased dramatically in response to $S$. exigua feeding, whereas in $B u$. orientalis only sinalbin concentrations were significantly higher in damaged than in undamaged control plants. Contrastingly, sinigrin concentrations in B. nigra did not increase significantly in response to herbivory.

\section{Discussion}

Both species of Pieris studied here oviposit and successfully develop on a large number of wild species of plants in the Brassicaceae (Feltwell 1982; Robinson et al. 2009). This includes species with which they probably have no evolutionary history due to small plant size and/or differing seasonal phenologies in the life-cycles of the plants and the herbivores (Yano and Ohsaki 1993; Harvey et al.
2007; Pfalz et al. 2007). Moreover, larvae of both species readily feed and are able to pupate on several novel crucifer species whose distributions do not naturally overlap with local populations of $P$. rapae or P. brassicae (J. Harvey unpublished; Dethier 1947; Johansson 1951; Benrey et al. 1998; Robinson et al. 2009). By contrast, the results of this investigation show that $\mathrm{Bu}$. orientalis plants were highly toxic to larvae of both pierids. Caterpillars grew much more slowly and mortality was at or close to $100 \%$ in both of the pierids when reared on $\mathrm{Bu}$. orientalis, whereas both species developed very successfully on the native crucifers, B. nigra and $S$. arvensis, with pupal survival of more than $70 \%$ on both plants. Although adults of $P$. rapae and $P$. brassicae preferred the native crucifers on which to oviposit, both species laid some eggs on leaves of $\mathrm{Bu}$. orientalis plants. Further assays also suggest that $B u$. orientalis is toxic to other specialist crucivores, including Plutella xylostella (J. Harvey, unpublished data) and Athalia rosae (C. Müller, personal communication).

Development and survival of the generalist noctuids on the three crucifers was mixed. Like P. rapae and $P$. brassicae, survival of $S$. exigua larvae was much higher on the native Dutch crucifers than on $B u$. orientalis. By contrast, larvae of M. brassicae readily fed on $\mathrm{Bu}$. orientalis and the survival of this herbivore species was significantly higher on this plant than on either $S$. arvensis or B. nigra. Both pierids and several other noctuids also performed very poorly on a German accession of Bu. orientalis. In line with results on Dutch $B u$. orientalis, larvae of $M$. brassicae developed very successfully on German plants, as did S. littoralis. This shows that the effects of $B u$. orientalis on herbivore performance vary dramatically amongst closely related noctuids, even congenerics, and that the ability to develop on this plant is not correlated with phylogeny but is speciesspecific. A cursory survey of $\mathrm{Bu}$. orientalis plants in Jena, Germany, in September 2006 also revealed that many plants were infested with mature $M$. brassicae caterpillars, whereas few other insect herbivores were found (J. Harvey and R. Gols, personal observations). This supports data from the development assays performed here.

GS have been shown to play a role in the success of some invasive plants in the Brassicaceae (Müller 2009). Chemical analyses of leaf tissues in the three crucifers revealed that the main GS found in $B u$. 
Table 3 Glucosinolate concentrations $($ mean \pm SEM) in undamaged and herbivoredamaged leaf tissues $(n=8)$ of Bunias orientalis, Sinapis arvensis and Brassica nigra

\begin{tabular}{llll}
\hline Plants species & Glucosinolates & $\begin{array}{l}\text { Undamaged } \\
\text { control }\end{array}$ & $\begin{array}{l}\text { Damaged by } \\
\text { S. exigua }\end{array}$ \\
\hline Bu. orientalis & 4-Methylsulfinylbutyl Gls & $0.73 \pm 0.07$ & $1.07 \pm 0.21$ \\
& 4-Methylsulfinylbut-3-enenyl Gls & $2.72 \pm 0.40$ & $3.80 \pm 0.68$ \\
& p-Hydroxybenzyl Gls & $25.8 \pm 2.0$ & $36.7 \pm 3.8^{*}$ \\
& Total & $29.2 \pm 2.3$ & $41.6 \pm 4.0^{*}$ \\
S. arvensis & 8-Methylsulfonyloctyl Gls & $0.54 \pm 0.13$ & $2.53 \pm 0.44^{* *}$ \\
& 9-Methylsulfinylnonyl Gls & $0.42 \pm 0.05$ & $1.87 \pm 0.28^{* *}$ \\
& 9-Methylsulfonylnonyl Gls & $4.25 \pm 0.81$ & $12.5 \pm 1.9 * *$ \\
& 10-Methylsulfinyldecyl Gls & $0.74 \pm 0.10$ & $2.03 \pm 0.29 * *$ \\
& 10-Methylsulfonyldecyl Gls & $1.73 \pm 0.32$ & $3.57 \pm 0.53^{*}$ \\
& p-Hydroxybenzyl Gls & $9.03 \pm 1.02$ & $21.9 \pm 3.7 * *$ \\
B. nigra & Total & $16.7 \pm 1.9$ & $45.5 \pm 5.2 * *$ \\
& Allyl GS & $15.9 \pm 2.7$ & $20.2 \pm 2.9$ \\
& Total & $15.9 \pm 2.7$ & $20.2 \pm 2.9$ \\
\hline
\end{tabular}

The compounds that are significantly induced by $S$. exigua feeding are indicated by $* P<0.05$ or ** $P<0.001$ based on twosample $t$-tests on $\log _{10^{-}}$ transformed concentrations active oviposition deterrents differ from the most active feeding deterrents, revealing that the plant employs two lines of defence against different stages of $P$. rapae. Very recently it has been found that, in addition to GS, Bu. orientalis produces an imidazol alkaloid, although it is yet to be determined if this secondary compound affects the development of specialist herbivores $(\mathrm{H}$. Vogel and M. Riechelt, unpublished data). Characterizing the function of this chemical will be the focus of future research.

Recent studies by Chew and colleagues (Keeler et al. 2006; Keeler and Chew 2008) examined interactions between the Nearctic butterfly, Pieris oleracea, and an exotic weed, the garlic mustard Alliaria petiolata in the eastern United States. This plant originates in Eurasia but become highly invasive in parts of North America in recent decades, displacing native plants, including other species of crucifers that serve as important food-plants for larvae of $P$. oleracea. The authors found that although female $P$. oleracea butterflies lay their eggs on A. petiolata, their larvae develop very poorly on it because the plant produces cynanide, as well as the GS alliarinoside, which are apparently novel compounds to which $P$. oleracea has not co-evolved (Cipollini and Gruner 2007). However, some populations of this herbivore are apparently adapting to this plant where it is abundant (Keeler et al. 2006).

In much of Europe, the main foodplants of pierid butterflies are short-lived annuals, such as $S$. arvensis and $B$. nigra. The seasonal phenology of these two 
species differs, with $S$. arvensis abundance peaking in May and June and B. nigra in July and August (Gols et al. 2008b). For multivoltine insects, this means that different generations of the same species may feed on different species of plants. In much of Europe, $P$. rapae is known to be trivoltine (three generations per year) and $P$. brassicae bivoltine (two generations per year; Feltwell 1982). This means that the first generations of both pierids may depend on S. arvensis as food plants, whereas second generations depend on B. nigra as food plants. By late August, when many butterflies are still active, most annual species have already seeded and lost their foliage, meaning that foraging adult females my find it difficult to locate suitable foodplants on which to oviposit. Unlike many annual crucifers, $B u$. orientalis produces a rosette in spring that persists well until late in the growing season. Mature larvae of $P$. brassicae and $P$. rapae have been observed, albeit in small numbers, on wild $\mathrm{Bu}$. orientalis plants in both Germany and The Netherlands (J. Harvey, personal observations). In line with these observations, in the oviposition choice experiments, Pieris females occasionally laid eggs on $\mathrm{Bu}$. orientalis, indicating that there is opportunity for host plant switches. This suggests if frequency dependent selection to adapt to novel plants is strong, this may eventually enable these herbivores to incorporate these plants into their diet (Keeler et al. 2006; Keeler and Chew 2008).

In summary, this study has reported that invasive plants may be toxic for non-adapted insect herbivores, but that ecological 'fits' can also occur by chance without the need for any evolutionary precedent. Mal-adaptation in both generalist and specialist herbivores to $\mathrm{Bu}$. orientalis supports the predictions of the 'enemy-release hypothesis' (Keane and Crawley 2002; Liu and Stiling 2006; Cincotta et al. 2009) and potentially the 'novel-weapons hypothesis' (Callaway and Ridenour 2004; Callaway et al. 2008) unless those few herbivores that can exploit this plant can numerically counter the absence of other attackers. Under reduced herbivore attack $\mathrm{Bu}$. orientalis may be able to allocate more resources towards growth, allowing it to outcompete native competitors, a process shown in other plants and described as the 'evolution of increased competitive ability' (or EICA) hypothesis (Meyer and Hull-Sanders 2008; Eigenbrode et al. 2009). These areas require detailed studies in the field, a process that is now underway in both the Netherlands and Germany.

Acknowledgments The authors wish to thank Roel Wagenaar for growing and maintaining plants, Gregor Disveld for providing ample greenhouse space in which to grow plants and conduct experiments, and André Gidding and Leo Koopman at Wageningen University for supplying eggs of the moths and butterflies. Michael Reichelt is gratefully acknowledged for his analyses of the glucosinolates.

Open Access This article is distributed under the terms of the Creative Commons Attribution Noncommercial License which permits any noncommercial use, distribution, and reproduction in any medium, provided the original author(s) and source are credited.

\section{References}

Agosta SJ (2006) On ecological fitting, plant-insect associations, herbivore host shifts, and host plant selection. Oikos 114:556-565

Agosta SA, Klemens JA (2008) Ecological fitting by phenotypically flexible genotypes: implications for species associations, community assembly and evolution. Ecol Lett 11:1123-1134

Agrawal AA, Laforsch C, Tollrian R (1999) Transgenerational induction of defences in animals and plants. Nature 401:60-63

Benrey B, Callejas A, Rios L, Oyama K, Denno RF (1998) The effects of domestication of BrassicaandPhaseolus on the interaction between phytophagous insects and parasitoids. Biol Con 11:130-140

Bernays E, Graham M (1988) On the evolution of host specificity in phytophagous arthropods. Ecology 69:886-892

Callaway RM, Ridenour M (2004) Novel weapons: a biochemically based hypothesis for invasive success and the evolution of increased competitive ability. Front Ecol Environ 2:436-443

Callaway RM, Cipollini D, Barto K, Thelen GC, Hallett SG, Prati D, Stinson K, Klironomos J (2008) Novel weapons: invasive plant suppresses fungal mutualisms in America but not in its native Europe. Ecology 89:10431055

Carter DJ (1984) Pest Lepidoptera of Europe with Special reference to the British Isles Junk, Dordrecht

Chew FS (1988) Biological effects of glucosinolates. In: Cutler HG (ed) Biologically active natural products for potential use in agriculture. American Chemical Society, Washington, D.C., pp 155-181

Cincotta CL, Adams JM, Holzapfel C (2009) Testing the enemy release hypothesis: a comparison of foliar insect herbivory of the exotic Norway maple (Acer platanoides L.) and the native sugar maple (A. saccharum L.). Biol Invasions 11:379-388

Cipollini D, Gruner B (2007) Cyanide in the chemical arsenal of garlic mustard, Alliaria petiolata. J Chem Ecol 33:85-94 
Dethier VG (1947) Chemical insect attractants and repellents. H.K. Lewis, London

Dietz H, Steinlein T, Winterhalter P, Ullmann I (1996) Role of allelopathy as a possible factor associated with the rising dominance of Bunias orientalis L (Brassicaceae) in some native plant assemblages. J Chem Ecol 22: $1797-1811$

Dietz H, Steinlein T, Ullmann I (1999) Establishment of the invasive perennial herb Bunias orientalis L.: an experimental approach. Acta Oecol 20:621-632

Ehrlich PR, Raven PH (1964) Butterflies and plants: a study in coevolution. Evolution 18:586-608

Eigenbrode SD, Andreas JE, Cripps MG, Ding H, Biggam RC, Schwarzlander M (2009) Induced chemical defenses in invasive plants: a case study with Cynoglossum officinale L. Biol Invasions 10:1373-1379

Engelkes T, Morrien E, Verhoeven KJF, Bezemer TM, Biere A, Harvey JA, McIntyre LM, Tamis WLM, van der Putten WH (2008) Successful range expanding plants experience less above-ground and below-ground enemy impact. Nature 456:946-948

Feeny P (1976) Plant apparency and chemical defense. Rec Adv Phy 10:1-40

Feeny P (1977) Defensive ecology of Cruciferae. Ann Mo Bot Gard 64:221-234

Feltwell J (1982) Large white butterfly, the biology, biochemistry and physiology of Pieris brassicae (Linaeus). Dr. W. Junk Publishers, The Hague

Fox LR, Morrow PA (1981) Specialization: species property or local phenomenon. Science 211:887-893

Gols R, Wagenaar R, Bukovinszky T, van Dam NM, Dicke M, Bullock JM, Harvey JA (2008a) Genetic variation in defense chemistry in wild cabbages affects herbivores and their endoparasitoids. Ecology 89:1616-1626

Gols R, Witjes LMA, van Loon JJA, Posthumus MA, Dicke M, Harvey JA (2008b) The effect of direct and indirect defenses in two wild brassicaceous plant species on a specialist herbivore and its gregarious endoparasitoid. Entomol Exp Appl 128:99-108

Gould F, Anderso A, Reynolds A, Bumgarner L, Moar W (1995) Selection and genetic analysis of a Heliothis virescens (Lepidoptera: Noctuidae) strain with high levels of resistance to Bacillus thuringiensis toxins. J Econ Entomol 88:1545-1559

Harvey JA, Witjes LMA, Benkirane M, Duyts H, Wagenaaar R (2007) Nutritional suitability and ecological relevance of Arabidopsis thaliana and Brassica oleracea as foodplants for the cabbage butterfly, Pieris rapae. Plant Ecol 189:117-126

Hopkins RJ, van Dam NM, van Loon JJA (2009) Role of glucosinolates in insect-plant relationships and multitrophic interactions. Ann Rev Entomol 54:57-83

Jalas J, Suominen J (eds) (1972-1994) Atlas Florae Europaeae: distribution of vascular plants in Europe vol 1-10. The Committee for Mapping the Flora of Europe and Societas Biological Fennica Vanamo, Helsinki

Janz N, Nyblom K, Nylin S (2001) Evolutionary dynamics of host-plant specialization: a case study of the tribe Nymphalini. Evolution 55:783-796

Jermy T (1984) Evolution of insect host plant relationships. Am Nat 124:609-630
Johansson AS (1951) The foodplant preference of the larvae of Pieris brassicae L. (Lep: Pieridae). Norsk ent Tid sskr 8:187-195

Keane RM, Crawley MJ (2002) Exotic plant invasions and the enemy release hypothesis. Trends Ecol Evol 17:164-170

Keeler MS, Chew FS (2008) Escaping an evolutionary trap: preference and performance of a native insect on an exotic invasive host. Oecologia 156:559-568

Keeler MS, Chew FS, Goodale BC, Reed JM (2006) Modelling the impacts of two exotic invasive species on a native butterfly: top-down vs. bottom-up effects. J Anim Ecol 75:777-788

Lankau RA, Strauss SY (2007) Mutual feedbacks maintain both genetic and species diversity in a plant community. Science 317:1561-1563

Liu H, Stiling P (2006) Testing the enemy release hypothesis: a review and meta-analysis. Biol Invasions 7:1535-1545

Louda SM, Rand TA, Russell FL, Arnett AE (2005) Assessment of ecological risks in weed biocontrol: input from retrospective ecological analyses. Biol Control 35:253-264

Meyer GA, Hull-Sanders HM (2008) Altered patterns of growth, physiology and reproduction in invasive genotypes of Solidago gigantea (Asteraceae). Biol Inv 10:303-317

Müller C (2009) Role of glucosinolates in plant invasiveness. Phytochem Rev 8:227-242

Müller-Schärer H, Schaffner U, Steinger T (2004) Evolution in invasive plants: implications for biological control. Trends Ecol Evol 19:417-422

Novotny V, Basset Y (2005) Host specificity of herbivores in tropical forests. Proc R Soc B 272:1083-1090

Perkins WDR, Jones RL, Sparks AN, Wiseman BR, Snow JW, McMillian D (1973) Artificial diets for mass rearing the corn earworm (Heliothis zea). USDA Prod Res Rep 154:7

Pfalz M, Vogel H, Mitchell-Olds T, Kroymann J (2007) Mapping of QTL for resistance against the crucifer specialist herbivore Pieris brassicae in a new Arabidopsis inbred line population, $\mathrm{Da}(1)-12 \times$ Ei-2. PLoS One 2:e578

Rask L, Andreasson E, Ekbom B, Eriksson S, Pontoppidan B, Meijer J (2000) Myrosinase: gene family evolution and herbivore defense in Brassicaceae. Plant Mol Biol 42:3-113

Renwick JAA (2002) The chemical world of crucivores: lures, treats and traps. Entomol Exp Appl 104:35-42

Renwick JAA, Huang XP (1996) Development of sensitivity to feeding deterrents in larvae of Pieris rapae. Entomol Exp Appl 80:90-92

Renwick JAA, Lopez K (1999) Experience-based food consumption by larvae of Pieris rapae: addiction to glucosinolates? Entomol Exp Appl 91:51-58

Robinson GS, Ackery PR, Kitching IJ, Beccaloni GW, Hernández LM (2009) Hosts-a database of the world's lepidopteran hostplants. Natural History Museum, London. Web site: www.nhm.ac.uk/research-curation/ research/projects/hostplants

Sachdev-Gupta K, Renwick JAA, Radke CD (1990) Isolation and identification of oviposition deterrents to cabbage butterfly, Pieris rapae, from Erysimum cheiranthoides. J Chem Ecol 16:1059-1067

Sachdev-Gupta K, Radke CD, Renwick JAA (1993) Antifeedant activity of cucurbitacins from Iberis amara against larvae of Pieris rapae. Phytochemistry 33:1385-1388 
Scriber JM, Slansky F (1981) The nutritional ecology of immature insects. Ann Rev Entomol 26:183-211

Siemann E, Rogers WE, Dewalt SJ (2006) Rapid adaptation of insect herbivores to an invasive plant. Proc Roy Soc B 273:2763-2769

Singer MS, Bernays EA (2008) Specialized generalists: behavioral and evolutionary ecology of polyphagous woolly bear caterpillars. In: Connor WE (ed) Tiger moths and woolly bears: behavior, ecology and evolution of the Arctiidae. Oxford University Press, Oxford, pp 103-114

Slansky F (1992) Allelochemical-nutrient interactions in herbivore nutritional ecology. In: Rosenthal GA, Berenbaum MR (eds) Herbivores, their interactions with secondary plant metabolites. Ecological and evolutionary processes, vol II, 2nd edn. Academic Press, San Diego, pp 135-174

Smallegange RC, van Loon JJA, Blatt SE, Harvey JA, Agerbirk N, Dicke M (2007) Flower vs. leaf feeding by Pieris brassicae: glucosinolate-rich flower tissues are preferred and sustain higher growth rate. J Chem Ecol 33:1831-1844

Thompson JN (1988) Coevolution and alternative hypotheses on insect/plant interactions. Ecology 69:893-895
Udayagiri S, Mason CE (1995) Host plant constituents as oviposition stimulants for a generalist herbivore: European corn borer. Entomol Exp Appl 76:59-65

van Loon JJA, Schoonhoven LM (1999) Specialist deterrent chemoreceptors enable Pieris caterpillars to discriminate between chemically different deterrents. Entomol Exp et Appl 91:29-35

Verhoeven KJF, Biere A, Harvey JA, van der Putten WH (2009) Plant invaders and their novel natural enemies: who is naïve? Ecol Lett 12:107-117

Vickerman DB, Trumble JT (1999) Feeding preferences of Spodoptera exigua in response to form and concentration of selenium. Arch Insect Biochem Physiol 42:64-73

Weis AE, Berenbaum MR (1989) Herbivorous insects and green plants. In: Abrahamson WG (ed) Plant-animal interactions. McGraw Hill, New York, pp 123-162

Woitke M, Dietz H (2002) Shifts in dominance of native and invasive plants in experimental patches of vegetation. Pers Plant Ecol Evol Syst 5:165-184

Yano S, Ohsaki N (1993) The phenology and instrinsic quality of wild crucifers that determine the community structure of their herbivorous insects. Res Pop Biol 35:151-170 